\title{
Development of Semiconductor Process Technology Using S-curve Main Parameter Value
}

\section{S-곡선 핵심가치변수를 활용한 반도체 공정기술개발}

Yong Mun Jeon ${ }^{1}$, Yong Won Song ${ }^{2}$

전용문 ${ }^{1}$, 송용원 ${ }^{2}$

${ }^{1}$ Engineer, SK Hynix Company, Republic of Korea, ymjun99@gmail.com

2 Professor, Dept. Nano \& Semiconductor Engineering, Korea Polytechnic University, Republic of Korea,ywsong@kpu.ac.kr

Corresponding author: Yong Mun Jeon

\begin{abstract}
This paper represents the study of laser repair process chuck using S-curve analysis. The need for this study is an important analysis of how systems have changed from the past to the present and can predict future systems. In this study, semiconductor wafers go through a series of ultra-fine processing. In the process, it was found that there is a problem in that the fuse is not blown as a result of confirming a fuse failure in the wafer chipset in the laser repair process. The problem is brought about by fine dust of $1.5 \mu \mathrm{m}$ or more accumulating in the protrusions near the chuck suction ring causing the wafer height to change. Accordingly, the function problem of the failure and the Main Parameter of Value (MPV) were defined as wafer deformation due to fine dust, and the contradictions were overcome to minimize the suction ring of the chuck. However, in the process of miniaturizing the wafer fuse, the minimum laser and accuracy limit of the facility was reached, and the laser repair process facility could not cope with the micro-processing and productivity improvement at the same time, thus, the S-curve research model was established with the direction of technology evolution. Furthermore, the future technology direction was established by using the and patents.
\end{abstract}

Keywords: TRIZ, Laser, S-Curve, Chuck

요약: 이 논문은 S-곡선 분석을 이용한 레이저 수리 공정 척의 연구를 나타낸다. 본 연구의 필요성은 과거에서 현재로 시스템이 어떻게 변화해 왔으며 미래 시스템을 예측할 수 있는지에 대한 중요한 분석이다. 본 연구에서 반도체 웨이퍼는 일련의 초미세 공정을 진행한다. 레이저 수리 공정에서 웨이퍼 칩셋의 퓨즈 고장을 확인한 결과 퓨즈가 끊어지지 않는 문제가 있는 것으로 확인됐다. $1.5 \mu \mathrm{m}$ 이상의 미세먼지가 척 흡착 링 근처의 돌출부에 축적되어 웨이퍼 높이가 변한다. 이에 따라 고장의 기능 문제와 핵심가치변수(MPV: Main Parameter of Value)를 미세먼지에 의한 웨이퍼 변형으로 정의하고, 모순을 극복해서 척의 흡착 링을 최소화하였다. 그러나 웨이퍼 퓨즈를 미세화 하는 과정에서 설비의 최소 레이저 및 정확성의 한계에 도달하고 레이저 수리 공정 설비는 미세공정 대응 및 생산성 향상을 동시에 대응할 수 없어 S-곡선 연구 모델은 기술 진화 방향으로 수립되었다. 또한, 특허를 활용하여 미래기술 방향성을 정립하였다.

Received: March 18, 2021; 1st Review Result: May 03, 2021; 2nd Review Result: June 18, 2021 Accepted: July 31, 2021 
핵심어: 트리즈, 레이저, S-곡선, 척

\section{1. 서론}

4차 산업혁명 시대에 반도체는 스마트기기, 인공지능, $5 \mathrm{G}$, 사물인터넷(IoT), 자동차 등에 탑재되는 주요 부품으로 주목받고 있으며, 또한 손바닥 크기의 모바일 기기, 몸에 착용하는 웨어러블 기기에도 반도체가 들어가면서 반도체 소형화의 중요성이 커지고 있다. 고객의 소형화 요구 사항을 보면, 패키지 평균 제품 크기의 변화는 ' 10 년 $100 \mathrm{~mm}^{2}$, $\sim^{\prime} 12$ 년 $62 \mathrm{~mm}^{2}, \sim^{\prime} 15$ 년 $38 \mathrm{~mm}^{2}, \sim^{\prime} 16$ 년 $18 \mathrm{~mm}^{2}, \sim^{\prime} 17$ 년 $8 \mathrm{~mm}^{2}$ 까지 집적화가 되는 상황이다[1][2][3].

스마트 시대에 부합하는 기술 혁신을 견인하기 위해서는 물리 공간/아날로그 형식에서 가상공간/디지털 형식으로, 폐쇄적 플랫폼에서 개방형 플랫폼으로, 대인 통신에서 사물 통신으로 발전되어야 하고, 성과 극대화형 연구개발(Research and Development) 방식 수립 그리고 특허 경영과 같은 체계 구축이 필요하다[4].

반도체의 지속적인 초미세공정 발전과 더불어 더 좋은 기술개발 전략을 수립하는 다양한 연구가 진행되고 있다.

미래예측 연구방법론의 대표적인 예를 들면, 델파이 기법(Delphi Technique), 시나리오, 전문가 패널, 환경 스캐닝, 추세 연장 기법 등이 있다. 여기서 델파이 기법은 다양한 전문가들에게 설문을 조사하여 그들의 의견을 분석하고 토론을 통해, 오류를 수정하고 합의점을 도출하여 미래 전략을 수립하는 방법이다[5]. 또 다른 방법은 특허 분석을 통해 기술계획서(Technology Roadmap)를 작성하여 활용하는 것이며, 대다수 글로벌 선두 회사들은 자신들의 분석법으로 매년 기술 전망을 작성하여 내부의 연구개발 전략을 수립하는 데 활용한다.

혁신 기술을 확보하는 핵심전략으로는 고객을 통합, 불연속적 변화의 가속화 대응, 가치와 능력에 집중하는 방향으로 진행되고 있다[6]. 따라서 일반 연구자가 새로운 미래기술 개발 전략을 쉽게 수립할 수 있는 방법론 개발이 필요하다.

\section{2. 내용}

미래의 기술을 개발하는 방법에 있어 개인의 주관성을 벗어나 객관적으로 연구하여 기술시스템의 진화 방향을 분석해 활용하였다.

러시아 과학자 알츠슐러(G. Altshuller)는 특허 분석을 통해 기술시스템의 발전과정을 분석하여 객관적인 진화 방향을 가지고 있음을 발견하였고, 그것을 기반으로 하여 창의적 문제해결 이론 '트리즈(TRIZ: Theory of Inventive Problem Solving)'를 개발하였다[7]. 그는 문제해결 과정에서 반복 사용된 사고의 패턴을 찾아 창의적 문제해결 이론을 개발하였으며, 기술시스템이 발전하는 과정에서 발견된 기술 진화 방향을 문제해결 방법론의 도구로 활용하였다. 트리즈 이론이 발전해 가면서 기술 진화 방향이 미래기술 개발 전략을 도출하는 방법론으로 발전시켜 나가게 되었다[8].

기술의 확산은 여러 상황에 의해서 진행되며 혁신의 관점에서는 공정 및 제품 그리고 부품의 혁신으로 구성된다. 이를 통해 성능 수준이 향상되어 기술의 확산으로 진화되고 S-곡선 형태의 발전을 이루게 된다.

제조 관점에서 보면, 기술개발보다는 비용 최소화로 이익을 극대화하는 방향성이 
정립되어 있음으로, 미래기술 해결 전략으로는 이상적인 아이디어를 제공하여 기술의 진화와 함께 새로운 제조 역량을 창출해야 한다.

따라서 본 논문에서는 트리즈 이론을 기반으로 개발한 기술 진화 방향에서 가장 핵심적인 S-곡선 법칙을 이용하여 반도체 기술 진화 방향 이론을 고찰하고자 한다.

\section{1 연구 모델}

제조 공정은 기술 진화 분석 모델로 레이저 공정의 기능 문제 도출 및 핵심가치변수를 정의하여 모순을 극복하는 1 차 $\mathrm{S}$-곡선의 발전 방향과 특허 기술의 발전현황 조사와 미래기술 예측조사와 더불어 2차 S-곡선 연구를 병행하였다. 따라서 레이저 공정의 S곡선 방향성을 [Fig. 1]과 같이 정립하였다.

핵심가치변수(MPV: Main parameter of value)

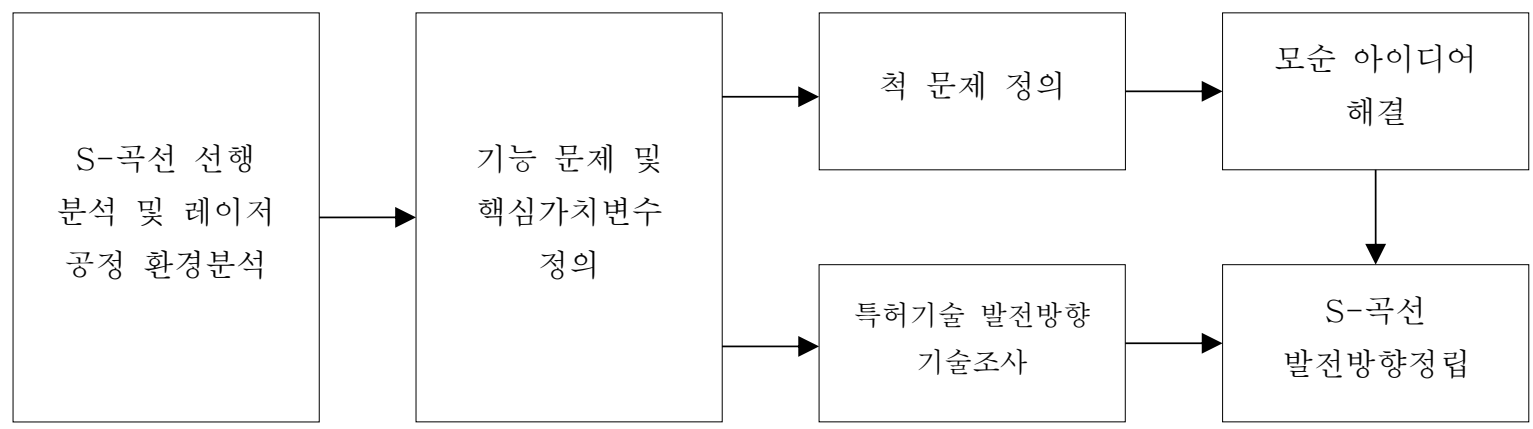

[그림 1] S-곡선 연구 모델 다이아 그램

[Fig. 1] S-curve Research Model Diagram

\subsubsection{S-곡선을 이용한 기술발전단계 분석}

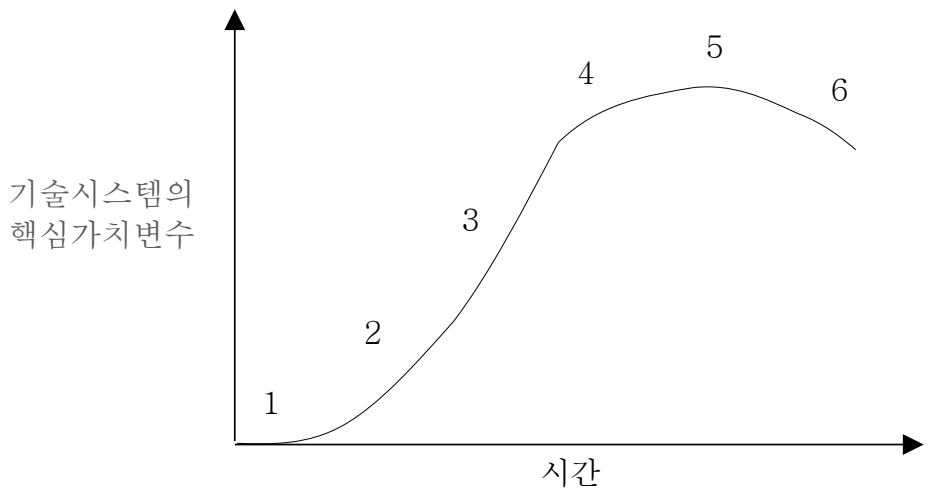

[그림 2] S-곡선 시스템의 라이프 사이클 모델

[Fig. 2] Life Cycle Model of the S-curve System

S-곡선 시스템의 라이프사이클 모델은 6단계 정의(1. 발명기, 2. 탄생기, 3. 과도기, 4. 성장기, 5. 성숙기, 6. 쇠퇴기)를 하고 있다[9]. 
발명기; 시스템은 아직 존재하지 않지만, 출현에 대한 조건이 개발되고 있다.

탄생기; 높은 수준의 발명으로 새로운 시스템이 등장하고 천천히 발전하기 시작한다. 그리하여, 고객을 전체 고객, 유효 고객, 목표 고객 등으로 정의한다. 또한, 차별화된 기능에 대해 핵심가치변수가 명확해야 하며, 전환 분석을 통해 미래의 실패를 예측하고 수정해야 한다.

과도기; 시스템의 운영 초기에 발생하는 새로운 문제는 근본적인 원인이 해결되지 않은 채로, 새로운 가치를 인식하기 시작한다. 하지만 과도기 단계에서 필요한 것으로는 미래성 높은 기술시스템이 아니라, 기존에 있는 상위 시스템에 적합한 자원을 활용하여 선두 시스템과 결합을 해야 한다.

성장기; 시스템은 최대 운영을 해야 하지만 자원이 대부분 고갈되어서 현장의 고질적인 문제가 해결되지 않는다. 이로 인해서 핵심가치변수가 증가하고, 사회 구성원의 관심이 커지며 시스템이 많은 자원을 요구하기 때문에, 불필요한 부분을 제거하는 손질(Trimming)과 요소(Element)도 증가하는 현상이 나타난다.

성숙기; 기존 시스템을 대체하기 위해서는 새로운 시스템이 나타날 때 시작된다. 현재의 시스템으로는 기술적인 한계점에 도달하여 또 다른 시스템을 요구하게 된다. 현재 기술의 방해 요인을 정리해 보면, 물리적 제약/기술의 제약/사회적 제약/상위 시스템 제약으로 나타나며, 중장기적 관점에서 비용 손실의 문제를 해결하고 서비스 기능을 발전시켜 나가야 한다. 또한, 장기적 관점에서 보면 차세대 시스템 개발과 많은 요소의 손질이 필요하다.

쇠퇴기; 기술이 추락하면서 현재 시스템을 완전히 대체하지 못해 발생하며, 새로운 $\mathrm{S}-$ 곡선이 탄생하게 된다.

$\mathrm{S}$-곡선 시스템의 발전을 평가하기 위해서는 정성적인 지표로 이상성(Ideality)을 가지고 설명할 수 있다.

$$
\text { 이상성(Ideality) }=\frac{\left.\sum \text { 유익한 기능(Useful Functions }\right)}{\left.\sum(\text { 비용(Cost) }+ \text { 해로운 기능(Harmful Function })\right)}
$$

이상성(1)은 시스템이 수행하는 유익한 기능의 총합을 시스템의 성능 개선을 위해 필요한 비용과 시스템에서 발생하는 해로운 기능의 총합으로 나눈 값이며, 시스템의 기술 발전은 이상성이 증가하는 것이다[5].

이상성(1)에서 기능은 다양한 변수로 평가할 수 있으며, 그중에서 시스템의 가장 중요한 개선 사항을 핵심가치변수로 정의한다.

\subsection{2 보조 저장장치의 $\mathrm{S}$-곡선 사례}

저장매체의 기술 발전과 저장 용량이 증가하고 있는데, 저장 단위의 기준은 [Table 1]과 같다.

[표 1] 저장 단위의 설명[10]

[Table 1] Storage Symbol Description [10]

\begin{tabular}{|c|c|c|c|}
\hline 기호 & 이진 접두어 기준 & 기호 & 이진 접두어 기준 \\
\hline 비트(Bit) & 1,0 & 바이트(Byte) & 1 byte $=8 \mathrm{bit}$ \\
\hline 킬로바이트(Kilobyte) & $1 \mathrm{~KB}=1024 \mathrm{Bit}$ & 메가바이트(Megabyte) & $1 \mathrm{MB}=1024 \mathrm{~KB}$ \\
\hline
\end{tabular}




\begin{tabular}{|c|c|c|c|}
\hline 기가바이트(Gigabyte) & $1 \mathrm{~GB}=1024 \mathrm{MB}$ & 테라바이트(Terabyte) & $1 \mathrm{~TB}=1024 \mathrm{~GB}$ \\
\hline 페타바이트(Petabyte) & $1 \mathrm{~PB}=1024 \mathrm{~GB}$ & 엑사바이트(Exabyte) & $1 \mathrm{~EB}=1024 \mathrm{~PB}$ \\
\hline 제타바이트(Zettabyte) & $1 \mathrm{ZB}=1024 \mathrm{~PB}$ & 요타바이트(Yottabyte) & $1 \mathrm{YB}=1024 \mathrm{ZB}$ \\
\hline
\end{tabular}

저장매체의 최소 단위는 비트(bit)이다. 비트는 ' 1 '과 ' 0 '으로 구성된 최소 단위이며, 바이트(B: byte)는 8bit로 구성되어 있다.

[Fig. 3] 내용에서 탄생기의 저장 능력을 설명해 보면, 1971 년 플로피 디스크는 $80 \mathrm{~KB}$, 1981년 콤팩트디스크는 650MB, 2000년 USB(Universal Serial Bus) 메모리는 8MB, 2004년 $\mathrm{SSD}$ (Solid State Drive) 외장은 $256 \mathrm{MB}$ 이다. $\mathrm{SSD}$ (Solid State Drive) 장치 발전 방향은 반도체 가격이 하락하고, 용량은 증가하면서 하드디스크를 대체하는 기술로 발전이 되었고, 2007년 SATA (Serial AT Attachment) 기반 SSD가 처음 등장하게 되었다. 2018년 512GB SSD 외장이 본격적으로 대중화되기 시작하였고, $1 \mathrm{~TB}$ 가 5 6만 원대의 가격대를 형성하고 있으며, 기술은 지속해서 발전하고 있다.

따라서, 각 보조 저장매체의 이상성을 높이기 위한 핵심가치변수는 저장 용량으로 정의한다.

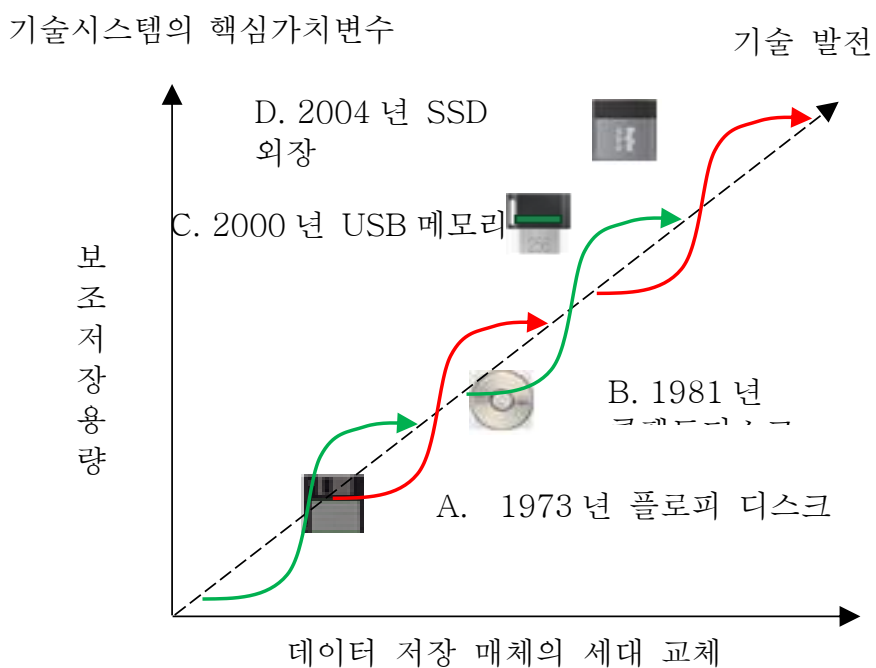

[그림 3] 보조 저장장치의 S-곡선

[Fig. 3] S-curve of Auxiliary Storage

\subsection{3 특허 분석을 이용한 $\mathrm{S}$-곡선 설명}

새로운 기술에서는 시스템의 성능 향상을 목표로 하고, 기능을 개선해야 한다. 예를 들면, 선풍기의 기능은 ‘공기를 움직인다’라고 정의한다. 공기를 더욱더 강하게 이동시키는 기능이 선풍기의 신뢰성과 비용 그리고 크기에 큰 영향을 미치게 된다.

따라서, [Fig. 4]에서 유익한 기능과 해로운 기능은 가장 중요한 개선 사항이기에 핵심가치변수로 정의된다. 이는 유익한 기능을 향상하고 해로운 기능을 감소함으로써 시장 점유율과 빠른 수익성이 보장되는 새로운 기술 투자로 발명(특허)의 수와 수준 증가가 예상된다[9]. 


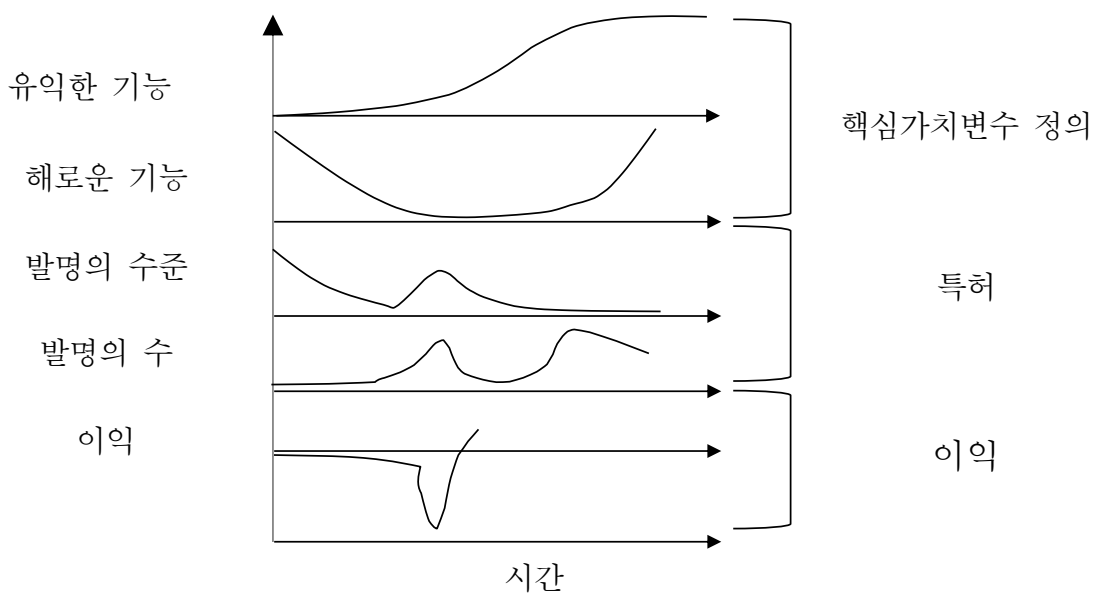

[그림 4] 핵심가치변수 S-곡선과 특허 관계[9]

[Fig. 4] Relationship between MPV(main parameter value) S-Curve and Patent [9]

트리즈는 특허 분석을 통해 S-곡선상에 정의하는 방법을 제공하며, Altschuller(1984)는 발명의 수 (출원된 특허)와 수준이 기록된 시간의 흐름에서 기술의 S-곡선 및 수익성과 관련이 있음을 확인하였고, 이는 기술의 전략적 결정을 할 수 있음을 시사한다.

\section{2 반도체 공정 S-곡선 연구}

\subsection{1 공정 설명 및 레이저 설명}

반도체 제조공정에는 웨이퍼 제조공정, $\mathrm{FAB}$ 제조공정, 웨이퍼 테스트, 어셈블리 \& 패키지 공정의 순서로 진행한다. 그중에서 웨이퍼 테스트 공정은 웨이퍼의 전기적 특성 및 동작 상태를 검사하여 양품과 불량품을 분류하고 불량품에 대해 수리 가능 여부를 판단해서 필요할 경우 레이저로 수리한다.

세부적 공정을 설명하면 기초 테스트(EPM: Electrically Parametric Measurement)는 전기적 소자 측정을 하며, 번인 테스트는 웨이퍼에 고온 및 기타 스트레스를 주는 공정, 고온 테스트는 웨이퍼에 고온 조건으로 테스트하는 공정, 저온 테스트는 웨이퍼에 저온 조건으로 테스트하는 공정, 레이저 수리 공정은 고온/저온 공정에서 진행된 메모리 테스트 데이터(MRD: Memory Repaired Data)로 퓨즈를 녹여서 전기 회로를 보정하는 공정, 상온 테스트는 레이저 수리 공정의 최종 수율을 확인하는 공정, 검사는 웨이퍼 테스트 공정의 품질을 확인하는 공정으로 구성되어 있다[11][12].

레이저 공정의 LASER(Light Amplification by Stimulate Radiation)는 ND: YLF (NeodymiumDoped Yttrium Lithium Fluoride) 원소로 구성되어 있으며 $1,321 \mathrm{~nm}, 1,064 \mathrm{~nm}, 1,047 \mathrm{~nm}$ 의 파장으로 $3 \mathrm{~W}$ 를 출력하고 있다. 실질적인 레이저는 $0.16 \sim 0.24 \mu \mathrm{j}$ 를 사용하여 순간적으로 고온의 열 $\left(1,400{ }^{\circ} \mathrm{C}\right.$ 이상 $)$ 을 웨이퍼의 퓨즈에 전달하여 퓨즈를 녹이는 역할을 한다. 레이저의 종류는 적외선 레이저(IR: Infrared laser), 맞춤형 적외선 레이저(TPIR: Tailored Pulse Infrared laser) 그리고 맞춤형 그린 레이저(TPGR: Tailored Pulse Green laser)로 구분이 된다.

레이저 수리 공정은 동작 기능 테스트 공정까지 진행하면서 발생한 부적합 셀 위치의 
퓨즈를 가열함과 동시에 기화하여 여분의 셀로 대체하는 공정이라 할 수 있으며, 레이저 크기는 퓨즈를 녹이는 데 있어서 가장 중요한 요소이다. 웨이퍼의 퓨즈 구조에 의해 레이저 공정의 최소 레이저가 결정되며, 줌 확장기(Zoom Expender), 초점 렌즈(Objective Lens), 레이저의 파장에 따라 레이저의 최소 크기(Spot Size)를 결정하게 된다.

\subsection{2 기술의 발전(웨이퍼 퓨즈와 설비)}

[Fig. 5]에서 웨이퍼 칩셋 퓨즈의 구성은 퓨즈 높이(a), 퓨즈 넓이(b), 퓨즈 간격(c)의 구조로 이루어져 있으며 칩셋을 축소하는데 필요한 항목으로 구성되어 있다. 따라서 퓨즈 넓이는 $1 \mu \mathrm{m}$ 에서 $0 . \mathrm{x} \mu \mathrm{m}$ 로, 퓨즈 간격은 $8 \mu \mathrm{m}$ 에서 $1 . \mathrm{x} \mu \mathrm{m}$ 까지 축소가 되었다.

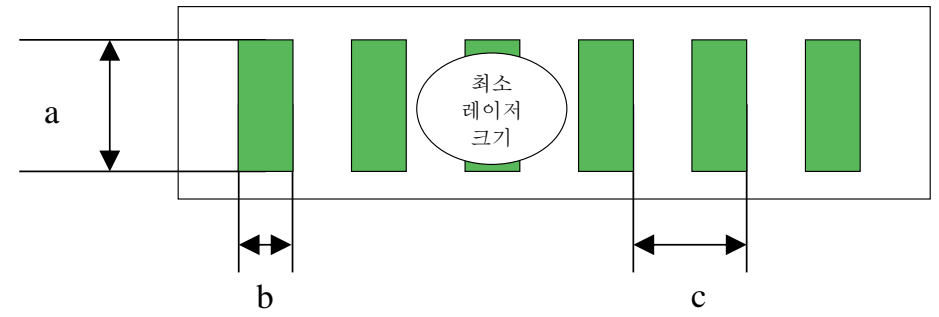

[그림 5] 웨이퍼 칩셋 퓨즈의 구성

[Fig. 5] Composition of Wafer Chipset Fuse

이로 인해, 미세공정이 한계점에 도달했고, 설비는 최소 레이저 크기와 정확도를 필요하여 [Table 2]와 같이 생산성 향상과 미세공정 대응으로 5단계 설비 발전이 이루어졌다.

[표 2] 환경 변화에 따른 레이저 수리 설비 핵심 사양

[Table 2] Key Specifications of Laser Repair Equipment according to Environmental Changes

\begin{tabular}{|c|c|c|c|c|c|c|}
\hline \multicolumn{2}{|r|}{ 항목 } & 단계 1 & 단계 2 & 단계 3 & 단계 4 & 단계 5 \\
\hline \multirow{5}{*}{ 생산성 } & 척 크기 [mm ] & 200 & 300 & 300 & 300 & 300 \\
\hline & 빔 종류 & 단일 빔 & 단일 빔 & 단일 빔 & 이중 빔 & 이중 빔 \\
\hline & 초당 펄스 $[\mathrm{K} / \mathrm{sec}]$ & 1.2 & 20 & 70 & 150 & 150 \\
\hline & 다중 영역 수리 & & Yes & Yes & Yes & Yes \\
\hline & 스테이지 이동수리 & & & & Yes & Yes \\
\hline \multirow{4}{*}{$\begin{array}{c}\text { 미세 } \\
\text { 공정 대응 }\end{array}$} & 최소크기 [ $\mu \mathrm{m}]$ & 2.5 & 1.8 & 1.6 & 1.2 & 0.8 \\
\hline & 파장 $[\mathrm{nm}]$ & 1047 & 1321 & 1321 & 1064 & 532 \\
\hline & 레이저 종류 & IR & IR & IR & TPIR & TPGR \\
\hline & 높이보정 & - & - & Yes & Yes & Yes \\
\hline
\end{tabular}

설비의 생산성 대응으로는 레이저 빔의 출력을 단일 빔에서 듀얼 빔으로의 전환, 레이저의 초당 출력 횟수(펄스)를 최대화, 한번 정렬/초점을 진행한 후 다중 영역에 대해 수리, 스테이지가 이동하는 상태에서 레이저 수리하는 방법들을 적용하였다. 
설비의 미세공정 대응으로는 레이저 파장의 변화와 구조적 개선을 통해 최소 레이저 출력을 구현, 전체적인 평탄도를 제어할 수 있는 높이 보정에 대해 기능 추가, 레이저 일부를 제어할 수 있는 맞춤형 레이저로 출력하는 방법들을 적용하였다.

\subsection{3 생산 환경 변화}

웨이퍼의 미세공정 기술이 지속해서 발전함에 따라 메모리 테스트 설비에서는 생산량의 증대가 필요하므로, 설비의 채널 증가 및 확장 프로브카드를 개발하여 테스트 시간을 줄여서 생산성 향상에 이바지하였다.

이에 따라 메모리 테스트 데이터(MRD: Memory Repaired Data) 수가 몇백 만개 수준으로 증가하여, 메모리 테스트 시스템에서 생산되는 웨이퍼를 레이저로 수리하는데 소요되는 설비의 수가 지속적인 증가로 이어졌고, 레이저 수리 공정은 [Table 2]의 5단계 이후 기술개발이 한계에 다다르게 되어 전자 퓨즈 공정을 검토하게 되었다.

\subsection{4 고장/기능/핵심가치변수 선정}

[표 3] 문제 상황[고장/기능/핵심가치변수]

[Table 3] Problem Situation [breakdown/function/main parameter value]

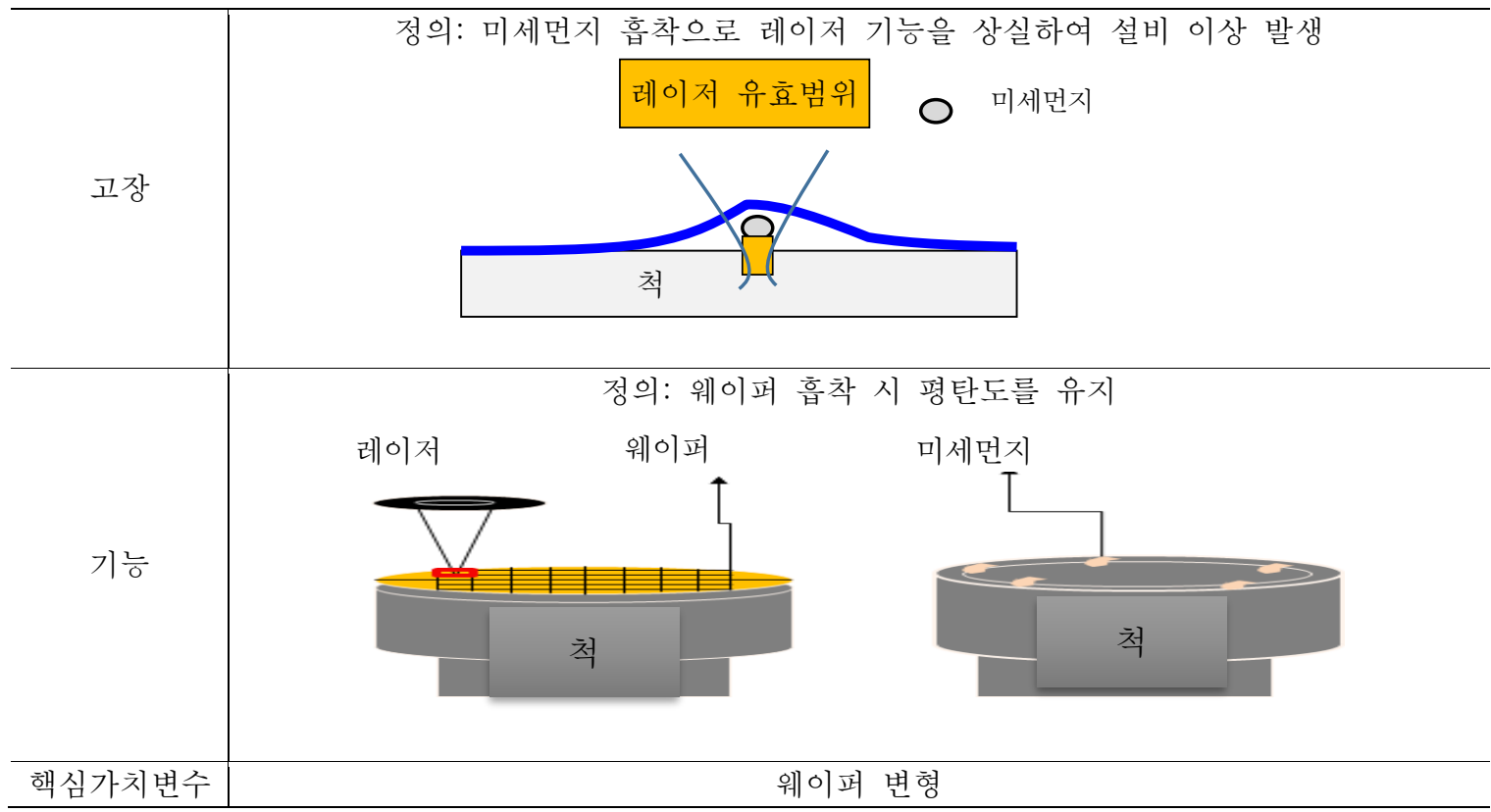

레이저 수리 설비의 기술적 한계로 시스템의 동작 과정에서 초미세먼지로 인해 레이저 기능 자체가 상실되었고 웨이퍼를 출하하는 과정에서 품질에 이상이 발생하였다.

여기서 [Table 3]의 문제 상황을 보면 웨이퍼의 퓨즈를 녹이는 과정에서, 척 위에 미세먼지가 흡착되어 웨이퍼의 높이 변화가 발생하고, 레이저의 유효 범위가 달라져서 설비에 이상이 발생했다. 이로 인해 척에서 웨이퍼의 흡착 시 평탄도가 변해서 레이저의 기능 문제가 발생하기 때문에 퓨즈의 손실/합선/파손/흔적 현상의 고장으로 이어진다.

여기에서 시스템의 기능과 성능을 좋게 하는 것이 핵심가치변수의 개선을 의미한다.

기술 예측을 위해 핵심가치변수를 명확화하면, 차세대 설비의 획기적인 이상성을 추구할 수 있다. 모든 제품과 프로세스 그리고 기술시스템은 시간이 지남에 따라 
진화한다. 고도의 진화된 시스템은 기능이 향상되어 효율성이 높고 기술시스템의 수준을 결정하는 데 사용되는 중요한 측정 척도이다.

정리해보면, 척의 기능은 웨이퍼를 흡착 고정하는 역할을 하고 있으며, 이때 내/외부의 요인에 의해 미세먼지가 척 표면에 붙어 있어 웨이퍼 변형이 발생하므로 이를 핵심가치변수로 선정하였다.

\subsection{5 특허 발전 현황}

반도체 레이저 수리 공정과 전자 퓨즈(Electronic Fuse) 공정 적용의 특허 제출 현황을 보면, 레이저 공정의 특허는 지속해서 증가하면서 2010년을 기점으로 제출의 빈도가 줄었으며, 전자 퓨즈의 관련 기술 또한 2010년을 정점으로 감소하고 있다.

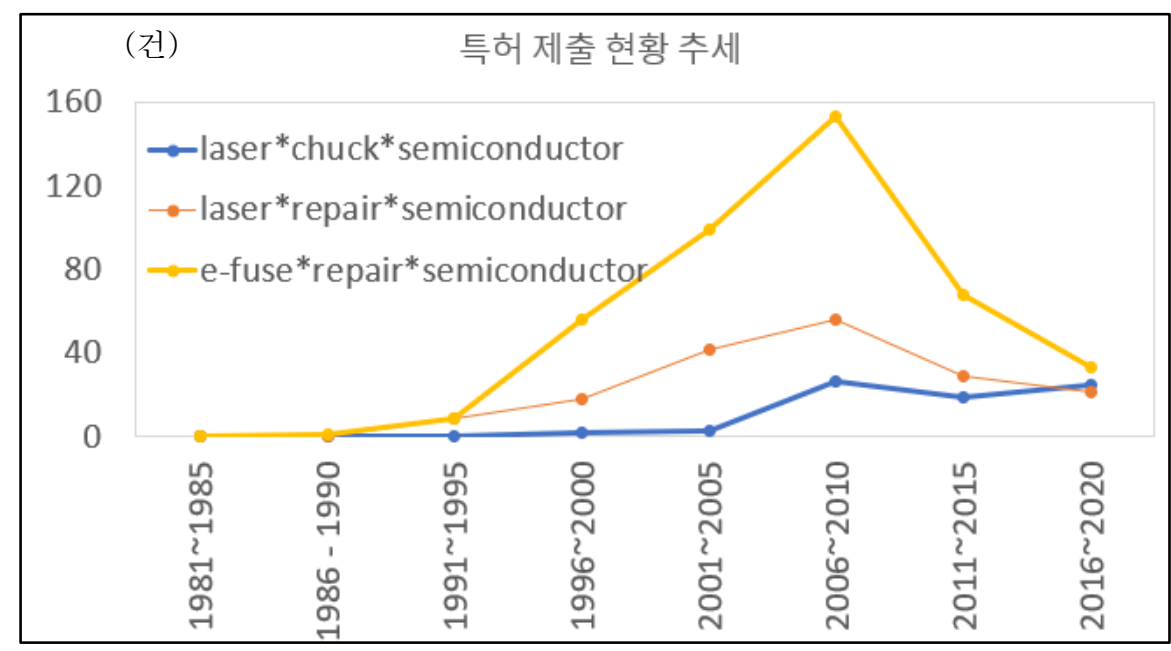

[그림 6] 레이저 수리 공정 관련 특허 현황 (키프리스, 데이터: 1981/01/01 2020/11/30)

[Fig. 6] Patent Status related to Laser Repair Process

특허 분석을 이용한 S-곡선 설명을 [Fig. 4]에서 보면, 특허의 수는 두 번의 증가 주기가 발생하는 것으로 보아 현 특허의 수는 발전 추세로 확인이 된다.

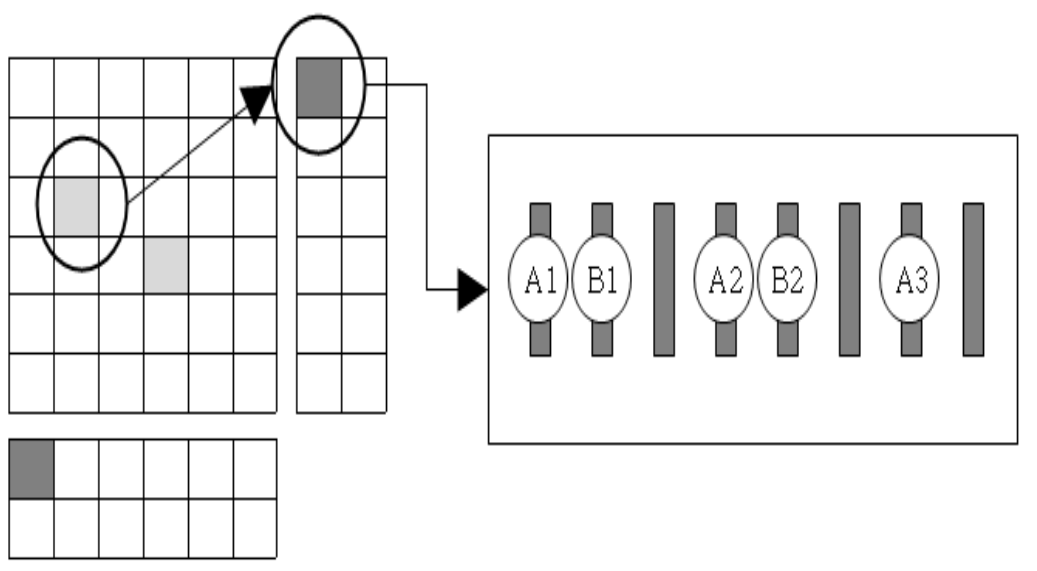

[그림 7] 웨이퍼 불량 칩셋의 셀 대체[13]

[Fig. 7] Replace Bad Chipset on Wafer [13] 
레이저 수리 기술은 웨이퍼의 불량 셀을 대체하는 기술로 레이저를 이용하는 공정이었으며, 웨이퍼의 퓨즈에 직접 레이저를 방출하는 방법이다.

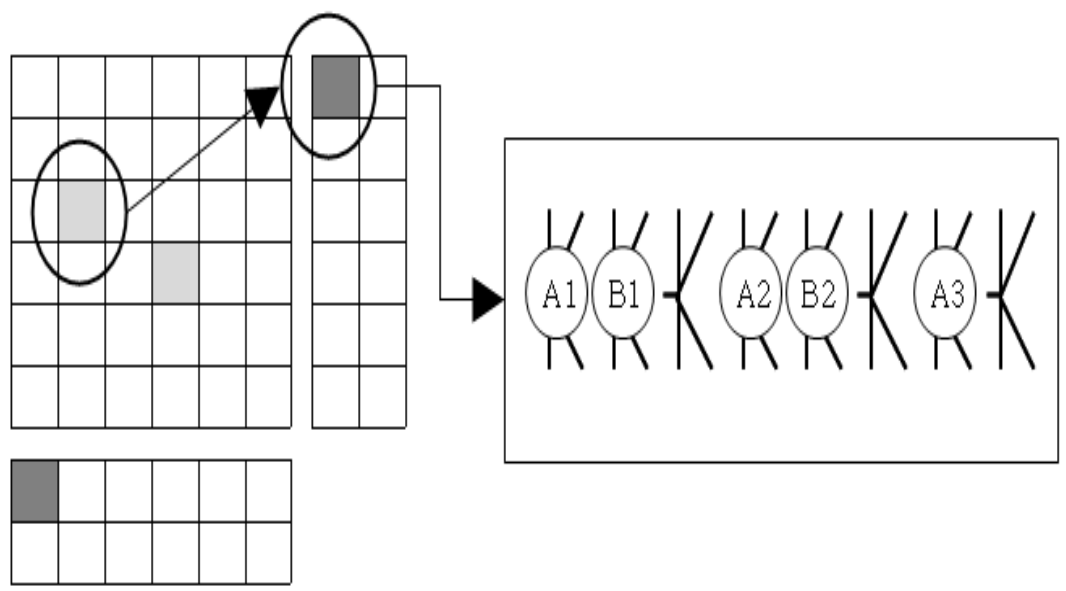

[그림 8] 웨이퍼 불량 칩셋의 전자 퓨즈 대체[13]

[Fig. 8] Replace Electronic Fuse of Bad Cell in Wafer Chipset[13]

전자 퓨즈 기술은 2010년 이후 현재까지 사용되는 기술이나, 독특하게 특허의 수가 크게 발전하였음을 시사하고 있다. 이는 부품의 혁신(설비의 특허)은 한계성이 있는 것으로 판단되며, 공정. 제품의 혁신(웨이퍼 설계 및 구조에 대한 특허)은 증가한 것으로 풀이된다.

마지막으로 척의 발전과 특허의 수는 횡보에 있음을 알 수 있다.

전체적으로 정리를 해 보면, 기존의 기술 적용에서 새로운 기술을 적용하게 될 때, 특허의 수가 증가하게 되는데 [Fig. 6]에서 보면 레이저 공정의 특허 수보다 향후에 적용될 전자 퓨즈 기술에서 특허의 수가 많다는 것은 주목할 만하다. 기존의 $\mathrm{S}$-곡선을 보면, 1 단계 S-곡선의 쇠퇴기에서 2 단계 $\mathrm{S}$-곡선의 주기가 시작하게 된다. 본 논문의 반도체 공정에서는 $\mathrm{S}$-곡선의 $\mathrm{X}$ 축을 시간 관점에서 보면, 핵심가치변수의 달성을 위한 기술 전략을 토대로 2단계 S-곡선은 틀림없이 이루어지고 있었다.

\section{3 반도체 공정에서의 척 개선 $\mathrm{S}$-곡선 사례}

\subsection{1 척의 핵심가치변수와 S-곡선 발전 현황}

척 흡착 링에서 고착된 미세먼지는 웨이퍼의 안착을 부족하게 하며, 웨이퍼의 높이를 변화시키는 문제가 발생했다. 이 문제의 해결을 트리즈 식으로 해석하면 웨이퍼의 흡착을 잘하기 위해서는 흡착 링은 넓어야 하고, 미세먼지에 의한 반응을 없애기 위해서는 흡착 링은 없어야 한다고 정의한다. 즉 “척 흡착 링은 있어야 하고 없어야 한다”라는 내용으로 정의되며, 이러한 상호관계가 해결될 수 없는 대립하는 상황을 모순이라고 한다. 이 모순적인 상황을 트리즈 분석을 통해 정의한 도식화는 [Fig. 9]와 같다. 


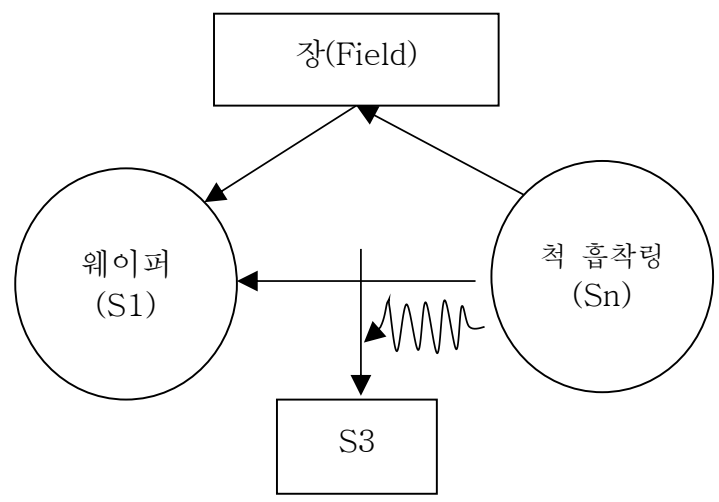

[그림 9] 장 분석 문제해결

[Fig. 9] Solving Field Analysis Problems

예를 들어 파리를 잡으려면 파리채를 이용하여 움직여야 한다. S1을 파리로 정의하면, $\mathrm{Sn}$ 은 손, 장은 파리채로 표현이 된다. 따라서, 손에서 파리로 전달되는 작용(Action)에서 나타나는 유익한 기능, 불충분한 기능, 해로운 기능을 표현한다.

작용에 대한 아이디어를 도출하기 위해 불충분한 기능과 해로운 기능은 표준 해결안을 적용하고자 하며, 문제에 대한 X-요소를 정의한 후 기계, 진공, 온도, 화학, 전기, 자기, 전자기, 바이오, 소프트웨어 장을 활용하여 아이디어를 도출, 때에 따라서 장을 혼합하여 아이디어를 적용하게 된다.

본 논문에서는 [Fig. 9]와 같이 척 흡착 링이 넓어서 웨이퍼에 전달하는 유해 기능에 대해 최소화하는 방법을 적용했으며, $\mathrm{S} 3$ 는 척 흡착 링과 웨이퍼의 작용을 최대한 억제하는 역할로 정의된다.

문제 해결의 핵심가치변수는 척의 흡착 링이 넓어서 미세먼지에 반응하는 웨이퍼 변형으로 정리했고, S-곡선에서 나타나는 발전 방향과 척의 흡착 링 발전사를 보면 [Fig. 10]과 같다.

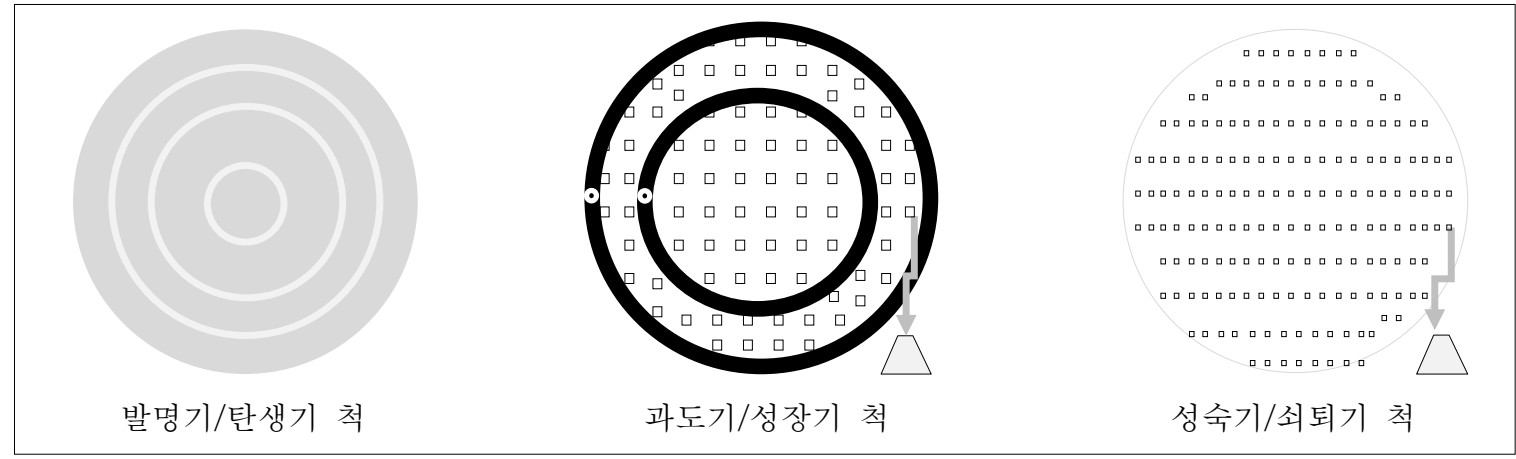

[그림 10] S-곡선 핵심가치변수(웨이퍼 변형) 최소화를 위한 척의 흡착 링 발전사

[Fig. 10] Advancement of the Chuck's Suction Ring to Minimize the S-curve Main Parameter Value (Wafer Deformation) 


\subsection{2 발명기/탄생기 척 표면}

발명기/탄생기 때의 설비 척 구조를 보면 [Fig. 10]과 같이 회색 부분이 웨이퍼에 닿는 면으로 접촉률이 상당함을 알 수 있다. 이 당시는 미세먼지에 영향을 조금 받는 제품 특성상 레이저 공정에서의 품질에 이상이 없어 고장 없이 운영 가능했다.

\subsection{3 과도기/성장기 척 표면}

반도체 미세공정의 발전과 함께 칩셋의 크기를 매우 작게 만들기 위해서 퓨즈의 배열에 많은 변화가 감지되었고, 퓨즈의 간격이 미세화되면서 척의 유익한 기능이 축소되었으며 해로운 기능이 출범하여 기술적인 이상성에 문제가 발생했다.

척의 유익한 기능이 웨이퍼를 평탄하게 만드는 역할인데, 미세먼지 흡착이 되면서 퓨즈 녹이는 공정에서 기능 문제가 발생했다. 따라서, 척 위의 웨이퍼에 닿은 면적을 최소화하는 엔지니어의 관심이 많았다.

\subsection{4 성숙기/쇠퇴기의 척 표면}

최종적으로 이루어진 척의 탑 모습을 보면, 트리즈에서 정의한 이상성, 즉 척의 표면(흡착 링 주변)에 미세먼지의 접촉을 최소화하는 전략과 일치하고 있다.

\subsection{5 척 표면 $\mathrm{S}$-곡선 발전}

시스템 척의 탄생기부터 쇠퇴기까지의 개선사항은 척의 기능인 웨이퍼 변형을 핵심가치변수로 정의하여 해결된 모습을 보면 [Fig. 11]와 같다.

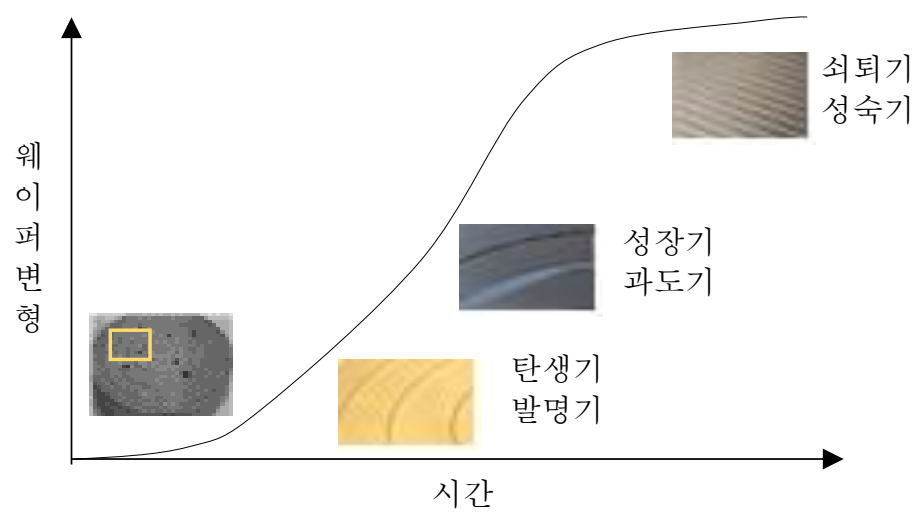

[그림 11] 웨이퍼 변형과 척 표면의 S-곡선 발전 방향

[Fig. 11] Wafer Deformation and S-curve Development Direction on the Chuck Surface

\section{3. 결론}

$\mathrm{S}$-곡선에서 관심 제품의 위치(발명기, 탄생기, 과도기, 성장기, 성숙기, 쇠퇴기)는 현재 기술에 대한 추가 투자, 연구 방향 설정 등 미래기술 개발 전략을 결정하는데 중요한 정보가 기술 관리자에게 제공된다. 핵심가치변수를 설정하고 시간에 따른 변화를 분석하면 현재 기술 수명과 향후 새로운 기술개발의 방향을 설정할 수 있다. 반도체 레이저 수리 시스템의 기술이 S-곡선 성숙기에 도달하였을 때, 차세대 기술을 기반으로 한 퓨즈 대체기술로 전자 퓨즈 기술이 접목되었고, 이로 인해 미세먼지가 발생해도 공정을 진행할 수 있어 최대의 품질 성능이 확보됐다. 
$\mathrm{S}-$ 곡선에서 핵심가치변수의 선택 및 성장 과정을 올바로 이해하고 분석할 수 있다면, 현재의 문제점 개선과 새로운 기술 도약을 추진할 수 있는 연구론임을 확인할 수 있다.

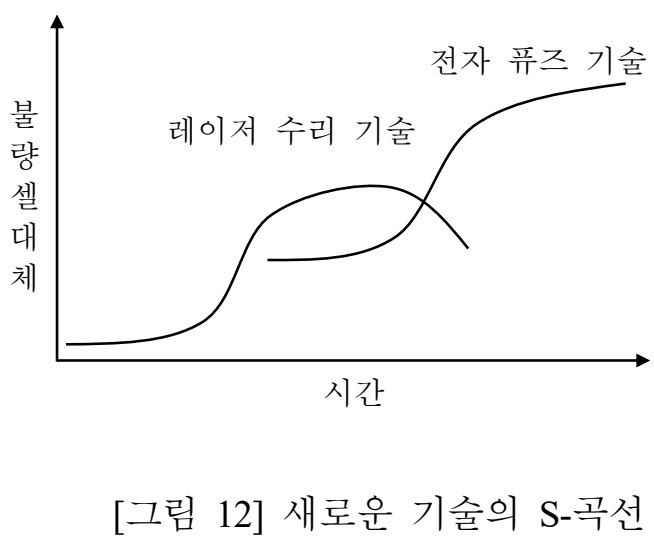

[Fig. 12] New Technology S-curve

본 논문의 연구 결과를 최종적으로 정리해 보면 다음과 같다.

- 핵심가치변수의 달성을 위하여 전자 퓨즈 기술을 적용함으로써 300 억/년의 비용을 절약 할 수 있었다.

- 핵심가치변수와 시간의 함수 속에서 기술 발전 방향에 대해 예측을 할 수 있다.

- 특허의 수와 수준을 파악하면 기술 발전 예측이 가능하며, 반도체의 새로운 공정 적용 을 통하여 이익에 대한 창출 시점을 알 수 있다.

- 핵심가치변수를 통하여 경영진의 미래기술 선택이 고려되기에 적절한 방법이라 할 수 있다.

- 향후 기술적 핵심가치변수를 선정하는데 설비의 측정 기술과 빅데이터의 자료화를 통 하여 기계학습(Machine Learning) 분석 결과의 의사결정 방식은 새로운 가치를 창출할 수 있다.

\section{4. 감사의 글}

This research was supported by Basic Science Research Program through the National Research Foundation of Korea (NRF) funded by the Ministry of Education (2018R1D1A1B07049244)

\section{References}

[1] https://www.samsungsemiconstory.com/2111, Aug 28 (2019)

[2] Jae-Kyung Kim, Jon-Mo Yoon, Bong-Soo Lee, Assessment of Competitive Edge of Major Global Semiconductor Vendors for Self-Driving Solutions (Level 3 and Above)- Evaluation of Qualcomm, Intel, and Nvidia, Asia-pacific Journal of Convergent Research Interchange, (2020), Vol.6, No.10, pp.165-180.

[3] Yong-Mun Jeon, Yong-Won Song, Solving Semiconductor Probe Card Problems Utilizing TRIZ and Data Analysis, ACTA TECHNICA NAPOCENSIS, Series: Applied Mathematics, Mechanics, and Engineering, (2020), Vol.63, No.3S.

[4] Heung-Nam Kim, R\&D strategy for technological innovation in the smart era. Korea Institute of Communication 
Sciences, The Journal of Korean Institute of Communications and Information Sciences, (2012), Vol.30, No.1, pp.3338.

[5] Yong-Won Song, Analysis of Technology Evolution Trends for Predicting Future Technologies, Asia-pacific Journal of Convergent Research Interchange, (2020), Vol.6, No.10, pp.123-136.

[6] Jae-Eok Lee, Chae-Yoon Lim, Wang-dong Kim, Dong-Gyu Kim, Innovation Strategy for Global Leading Companies, Science \& Technology Policy Institute, (2003), pp.1-189

[7] G. S. Al'tshuller, A. Williams, Creativity as an exact science : the theory of the solution of inventive problems, New York : Gordon and Breach Science Publishers, (1984)

[8] https://triz-journal.com/, Jan 05 (2001)

[9] https://triz-journal.com/, Michael S. Slocum, Technology Maturity Using S-curve Descriptors, Dec 01 (1998)

[10 http://it.chosun.com/site/data/html_dir/2013/04/16/2013041685015.html, (2013)

[11] https://www.skcareersjournal.com/1203, Aug 2 (2018)

[12] Young Deok Kim, Case study of quality improvement of semiconductor fabrication process in slump state : focused on the case of H company, College of Business \& Government, Yonsei University, Master's Thesis, (2010)

[13] http://www.koreatest.or.kr/sub02/2008data/report/08-030.pdf, Mar 18 (2008) 